\title{
THE INVESTIGATION OF INDONESIAN EFL LEARNERS' ERRORS ACROSS THREE PROFICIENCY LEVELS
}

\author{
Saudin \\ English Department, Politeknik Negeri Bandung, Indonesia \\ Email: saudin@polban.ac.id
}

\begin{abstract}
The study analyzed the errors made by students across three different levels of proficiency (Advanced, Intermediate and Elementary) in their writing pieces. Three students were selected purposively to represent their respective level. So, nine pieces of writing altogether were to be investigated in this study. The errors committed by the purposive samples were first grouped into fifteen linguistic classifications such as verb form, preposition, mechanics and so forth, then subsumed under two broader categories: negative interlingual and intralingual transfer. The investigation revealed that the learners made more errors of intralingual transfer than those of negative interlingual one. However, in terms of errors based on the linguistic classifications, this study showed surprising findings. Advanced learners, though committing the least errors, performed worst by making errors in the most linguistic classifications (seven altogether): plural-singular form, omission of constituent, verb form, article, vocabulary, pronoun and comparative. Intermediate learners came next by committing errors in less number of linguistic areas (five), namely mechanics, preposition, derivative, auxiliary verb and clause formation. Elementary learners came last by giving poor performances on the least number of just three linguistic areas: tense, word order and genetives. Across levels, however, three areas (consecutively mechanics, plural/singular form and omission of constituent) appeared to be where errors were most commonly committed. With findings as such, the study is expected to impart theoretical contributions to SLA, especially to studies on error analysis. The findings hopefully can also inspire teachers to teach students of these three proficiency levels in ways that meet their needs more.
\end{abstract}

Keywords: purposive samples, linguistic classifications, negative interlingual tranfer, intralingual transfer, SLA.

\section{INTRODUCTION}

Developmental stages of learning a foreign language, especially the early ones, are commonly characterized BY error-making. The errors can vary from mechanics (wrong spelling and uses of punctuation), phonology (an erroneous pronunciations of certain words) to morphology and grammar (the use of energic instead of energetic, wrong subject-verb agreement, for example). Errors in learning an L2 are generally viewed as 'unwanted forms' (George, 1972 cited in Ellis, 1994, p. 47), which are overtly different from the native speaker's grammar. It is also said that errors indicate learners' interlanguage competence (Dulay \& Burt, 1972 in Brown, 1994). 
In making an error, learners do not realize it was wrong or inappropriate so they could not correct it directly. Therefore, errors occur due to learners' deficient competene in the language to date. For this reason, an error is considered as an error of competence, different from a mistake, which is an error of performance since it is immediately realized and corrected when it occurs by the performer (de Bot et al., 2005). Taking the meaning of error into account, error analysis is therefore an analysis on learners' linguistic errors which result from their insufficient competence in the system/grammar of the language at a particular time in the developmental stage of learning it.

Richard (1992) suggests that research on error might be conducted with the purpose of obtaining information about learners' common errors (usually divided into some linguistic classifications) and find the causes for the errors (widely categorized into two types: negative interlingual transfer and intralingual transfer). Besides, error analysis could be conducted to identify strategies learners used in language learning. Conducting research on learners' errors therefore brings about fruitful results. If research on errors is conducted systematically, it can become a means for teachers to find ways and develop strategies of teaching to benefit the learners. It can certainly help teaching practitioners with their preparation for materials to teach.

It is known that error analysis has long been developed. In the 1950s and 1960s when Audiolingual Method was still prevalently used in language teaching, error analysis had been adopted in language pedagogy with the purpose that learners could better learn an L2 (de Bot et al., 2005). Further, it was believed that learners' old habits of using their L1 would interfere with their leaning of an L2, causing errors in the L2, especially when the two languages were different. The two languages were compared systematically using a certain structural pattern known as the Contrastive Analysis Hypothesis ( $\mathrm{CAH})$, which was claimed by its proponents could forecast the majority of errors made in the langauge learned (de Bot et al., 2005).

In these early error analysis, French (1949) provided detailed discussions of common learner errors. His work was followed by Lee (1957), who reported his investigation of around 2,000 erroneous forms in some Czechoslovakian learners' writing pieces. The errors were categorized into several (linguistic) classifications such as misspellings, wrong punctuation, wrong use of tenses, non-English constructions and misuse or omission of articles. Lee (1957) suggested that error analysis inspired teachers with ideas on how teaching time should be allocated. However, these early error analyses lack a rigorous methodology and theories for explaining the importance of errors in the process of learning a language due to the fact that 
Audio lingual Method, which underpinned traditional error analyses, has lost its ground to account for how language is acquired (Ellis, 1994).

Neglected for quite some time by many researchers, error analysis has now regained its popularity (Ellis, 1994). That has happened since Corder published his seminal article 'The significance of learner's errors' (1967). He asserted that learners' error-making represents the grammar or system of the language they have learned at a particular stage of development although the system is still not the correct one. As such, errors are then important in three respects. According to Corder (1974), the firts respect is to the teacher, errors tell how far the learners have suceeded in reaching the objectives and what is left for them to learn. The second respect is to the researcher, errors provide him/her with evidence of how language is learned, what strategies the learners are using to discover themselves the system of the language they are learning. The third respect is errors are essential to the learners themselves as error-making is as a resource used by them in order to learn. That is a strategy employed by not only children acquiring their mother tongue but also by those learning a second language (de Bot et al., 2005).

Taking the significances of errors, this study aimed at investigating common errors made by learners from three different proficiency levels. They were Elementary, Intermediate and Advanced. To be more precise, the study was conducted to investigate the profiles of error made by learners across these three levels. As such, this study is expected to make contributions to the theory of SLA (Second Language Acquisition) in that the study can reveal some certain features of language that can be successfully acquired and some others which cannot at a particular time in these three groups' language development stages. This study is also expected to inspire teaching practitioners the ways of how to teach students from these three different proficiencies more fruitfully. To formulate its objectives, the research tries to seek the answers to the three research questions below:

(1) What types of errors in terms of linguistic classifications are made by Indonesian EFL learners from three different levels, namely Elementary, Intermediate and Advanced?

(2) What can be learned from the profiles of linguistic classification-based errors across these three proficiency levels?

(3) What is the main source of those linguistic classifications of errors, negative interlingual or intralingual transfer? 


\section{THEORETICAL FRAMEWORK}

After Corder's seminal work 'The significance of learner's errors' (1967) was published, it could be safely said that Error Analysis (EA) generally replaced Contrastive Analysis Hypothesis $(\mathrm{CAH})$ as a framework to analyze learners' errors. In EA, it is not thoroughly learner's L1 that becomes the starting point for analyzing or predicting his/her errors in learning an L2 as it was in $\mathrm{CAH}$; rather, it is his/her interlanguage that is taken up as the starting point for the analysis (de Bot et al., 2005). Interlanguage, a technical word first coined by Selinker (1972), is a system of language developed by an L2 learner who is approximating the L2 but considered still preserving some features of his/her L1. Interlanguage is therefore a linguistic system which is not either that of the L1 or that of the L2; it is a third language that has its own system, its own vocabularies and so forth applied by learners not fully proficient yet at any particular stage in their learning development (see http://www.timothyjpmason.com/WebPages/LangTeach/Licence/CM/OldLectures/L7_Interl anguage.htm).

As further studies have been indicated, it is clear that this interlanguage, where learners show their errors of competence, results from several factors. These factors consist of three sources. Richards (1971in Ellis, 1994, p. 58) elaborates them as follows:

(1) Interference errors refer to the type of errors resulting from the use of elements from L1, while speaking L2. For example, Indonesian learners sometimes use 'not can' instead of 'cannot' or combine 'make' and 'damage' to form a malformed collocation of 'make damage', instead of 'do damage'. This interference error, also called negative transfer of L1 in L2, is so important that Ellis states that 'no theory of L2 acquisition is complete without an account of L1 transfer' (1994, p. 341).

(2) Intralingual errors are errors caused by learners' insufficient mastery of the language system learned such as faulty generalization, wrong application of rules and failure to learn the right condition to apply certain rules appropriately. For example, as a learner has known that most of verbs take infinitival complements, he/she comes up with a sentence 'He made me *to rest.' Other example is related to an error in sentence or clause formation such as 'I don't know what time *is it' instead of 'I don't know what time it is.'

(3) Developmental errors are types of errors that result from the learner's efforts to develop hypotheses about the language learned on the basis of limited knowledge such as using 'choosed' for the past form of 'choose', assuming that 'choose' is just the same as most other verbs which are just added -ed to form the past tense. 
Another linguist, Brown (1994, pp. 213-214), proposes four sources of errors. The first and the second one are called interlingual transfer and intralingual transfer, similar to those suggested by Richards above. Brown's third source of errors is termed 'context of learning' where errors are committed due to the teacher's incorrect explanation, the inaccurate illustration of a structure written in the textbook, or memorized grammatical patterns not put in an appropriate context. The fourth source is 'communication strategies.' These are actually learning styles adopted by learners to enhance the quality of communication in order to convey their messages. Sometimes, the strategies can turn out to be a cause for errors. For instance, it is possible for one ESL learner to say 'For the *well done of our company, we have to ... 'instead of 'For the smooth running of our company, we have to ... .'

However, it is not always easy to identify the differences between especially intralingual and developmental errors in Richards' categories. Similarly, it is difficult to distinguish intralingual transfer, on the one hand, from context of learning and communication strategies, on the other hand, in Brown's categories above. It is for those reasons, a lot of researchers have operated with a general distinction between negative interlingual and intralingual transfer as sources of errors made by L2 learners (Ellis, 1994; Ferris, 2002; Schachter \& Celce-Murcia, 1977). Therefore, the two categories are adopted in this study as the sources of errors made by its participants.

Before (the sources of) errors are categorized into these negative interlingual and intralingual transfer, studies on error analysis commonly identify first the linguistic classifications or types of errors made by learners. To describe the types of errors, several choices exist (for detail, see Ellis, 1994, pp. 55-56). The first one is linguistic classification of errors, where errors are broken down into for example verb form, omission of constituents, sentence formation, article, and preposition. The second choice is a surface strategy taxonomy, where errors are classified into for instance omissions (the non-existence of a linguistic item that must appear in an appropriate utterance), additions (the opposite of omissions), misinformations (the employment of the wrong morpheme or structure), and misorderings (the inappropriate placement of a morpheme or word in an utterance). The third alternative, proposed by Corder (1974), is a framework consisting of (1) presystematic errors which occur when the learner is unaware of the existence of a particular rule in the target language, (2) systematic errors which occur when the learner has discovered a rule but it is the wrong one, and (3) postsystematic errors that occur when the learner knows the correct target language rule but uses it inconsistently (i.e. makes a mistake). 
In this research, the linguistic error classification which belongs to the first type was chosen in describing the errors made by the learners. This is because the type has specific terms which are more familiar for teaching practitioners, compared with those of the other two types. So, the choice of the first type will benefit both teachers (and learners as well) as it will help to call learners' attention to areas of needed improvement and provide valuable diagnostic information to teachers to give feedback to their students or to organize teaching presentations in order to obtain higher impacts of the teaching on the part of the learners' language improvement.

However, in this study the linguistic error classifications were expanded. Other linguistic errors, besides the five types mentioned above (verb form, omission of constituents, sentence formation, article, and preposition), were included. They were for example pronoun, word order, tense, plural/singular form, mechanics (which includes spelling, capitalization and punctuation), as suggested by Hartono (2001). Further other classifications were added too like comparative, traditionally known as degrees of comparison, derivative, also called parts of speech, vocabulary (i.e. wrong choice of word), genetive (mainly the use of 's), clause formation (offered to replace sentence formation to identify errors in not only the main but also subordinate clause formation), and auxiliary verb (especially the unnecessary inclusion of be) to cover common errors made by Indonesian learners of English. A note is necessarily given to plural/singular form that they cover not only plural/singular nouns but also plural/singular verbs, known as subject-verb agreement.

\section{METHOD}

The study adopted qualitative methods and made use of quantitative instruments such as tables to illustrate its findings. By the method, in-depth analysis of the participants' writing or the learners' corpus, was carried out to obtain detailed information from it. Quantitative instruments were made use of to display the results of the error analysis. The results included the quantities and percentages of the types of the linguistic classifications of errors, and the quantities, percentages and frequencies of errors in terms of negative interlingual transfer and intralingual transfer, namely the two sources of the linguistics classifications of errors.

In analyzing errors made by the participants, this research took four steps. The four steps were based on the suggestions made by Corder (1974) on how this Error Analysis research was supposed to be conducted. They were as follows: 


\section{(1) Samples of learner texts}

Nine participants' writing pieces were selected purposively. The pieces were produced in a test, following the instructions provided with writing prompts. As the study was a cross-sectional, the collection of writing data were carried out within one particular period of time, not over time. However, the study was expected to account for the process of how language was acquired as the writing pieces were taken from learners of three different proficiency levels.

(2) Identification of errors

A linguistic item or unit is identified as an error when it constitutes an unacceptable form from the system of the language learned. This follows the suggestion put forward by Ellis (1994, p. 54). In the study, the norms of the target language taken were of British and/or American English.

(3) Description of errors

This step refers to the account of comparing the learner's erroneous language productions with the correct versions of those productions in the target language, English. In this research, fifteen linguistic classifications were chosen to identify/describe the errors. The reason for the choice is that the classifications consist of terms which are well known to English teaching practitioners. They generally correspond to those found in structural syllabuses and language textbooks used in teaching structures.

\section{(4) Explanation of Errors}

This fourth step is an effort to explain the errors. It is related to the identification of the source of the errors, that is, finding the reason why they are committed. This step is crucial as it is an effort to explain the processes that account for the acquisition of a language (Ellis (1994). In other words, the stage refers to the broader categorizations under which the linguistic classifications of errors are subsumed. The categorizations adopted in this study were negative interlingual and intralingual transfer, as having previously been elaborated.

\subsection{The Participants and Research Site}

The learner participants of this research were from one Indonesian long-established English course which offered its English programs in three levels, Elementary, Intermediate and Advanced. The participants were forty altogether in number and from three classes of different levels (10 students from Elementary, 17 from Intermediate and 13 from Advanced). They all were asked in a test to write one of three topics suggested, using around 150-200 words for Elementary, 250-300 words for Intermediate and 350-400 words for Advanced level. Three 
participants from each level were then selected purposively to be the representatives of the groups of high-, middle- and low-achiever students in their classes. From them, nine pieces of writing were collected and analyzed to reveal the profiles of errors made in their writing texts.

\subsection{Samples of Error Analysis}

Some data of the students' writing tests presented below as the samples of how the data were analyzed. In the presentation, in line with the steps of error analysis already explained, errors were identified first by referring to the target language standard norms, then labeled by using the linguistic classifications or terms as discussed previously. Finally, the linguistic terms used to label the errors were further categorized, based on the sources of errors, into negative interlingual (INTER) or intralingual (INTRA) transfer. Below are the samples of the analysis, taken from parts of the students' writing across the three proficiency levels.

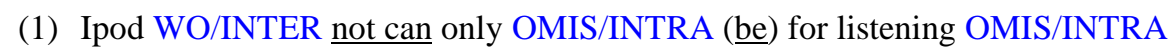
(to)ART/INTRA a music (Taken from the High

Achiever's writing test of Elementary Level).

In the sample, four errors were made by this student of Elementary level. Firstly, he wrongly ordered the two lexical items not can, which should be cannot. Therefore, in terms of linguistic classification, the error belongs to word order (WO). The source of this linguistic error is negative interlanguage transfer because there is an interference of Bahasa Indonesia 'tidak (not) bisa (can)'.In his second and third errors, the students did not provide 'be' and 'to' (omission of constituent). Because these errors come from his lack of mastery of the system/grammar, the source of errors is a type of intralingual transfer. Lastly, he made an error in the linguistic classification of article because he used the article ' $a$ ', which should be absent from the noun 'music' since it is an uncountable noun. Again, this error shows the student's limited competence in the system of the language so it belongs to intralingual transfer.

(2) PREP/INTRA In the other side, money brings DERV/INTRA

Greedy PREP/INTRA of someone (Taken from the High

Achiever's writing test of Intermediate Level).

In the sample above, this student of Intermediate level made three errors in one sentence. The first error is a linguistic classification of errors in using prepositions. Instead of 'in', the preposition is supposed to be 'on' to form the contrastive conjunction 'on the other side'. In the second error, its linguistic classification is of derivative. The lexical item needed here should not be 'greedy', which is an adjective but 'greed', which is a noun. The third error 
is the wrong use of the preposition 'of', which should be 'to' as a common preposition that is expected to co-occur with the verb 'bring'. All the three errors belong to the source of errors in intralingual transfer because the learner shows limited competence in the grammatical rules of the language.

(3) Usually, new features are so useful but more sensitive, so that we must control and update PRON/INTRA it MECH/INTRA(;)VOC/INTRA whether not, the pay for the maintenance can be expensive ... and of course it'll VFORM/INTRA wasting a lot of money (Taken from the Middle Achiever's writing test of Advanced Level).

This last sample of the analysis shows Advanced learner made four erroneous constructions. Firstly, the error is the pronoun 'it' which was wrongly used. The right one should be 'them' since it is the plural noun 'new features' which are referred to here. Secondly, the error is related to mechanics; that is, a punctuation of semi colon or full stop is needed here but it was not provided by the learner. Thirdly, a wrong word was used. Instead of 'if', the learner chose the lexical item 'whether', which of course is not synonymous with 'if' in the context of the sentence. Lastly, the error is related to linguistic classification of error in verb form. The verb 'wasting' is supposed to be 'waste' as it follows the auxiliary verb 'will'. Since all errors result from the learner's inaccurate use of rules or failure to apply rules appropriately, the errors are of intralingual transfer.

\section{FINDINGS AND DISCUSSION}

Error analysis, conducted to answer the three research questions, has brought about some results. The results are tabulated below in two tables. Table 1, which aims at responding to the first and second research question, shows the distribution of linguistic classification-based errors in terms of numbers and percentages across the three proficiency levels. Table 2, compiled specifically to address the third research question, displays the proportions of the negative interlingual and intralingual transfer as the sources that account for the linguistic classification-based errors made by the participants across levels.

\subsection{Research Question 1:}

What are the types of errors in terms of linguistic classifications made by Indonesian EFL learners from three levels of proficiency (Elementary, Intermediate and Advanced)?

As shown in Table 1, there are fifteen linguistic areas in which the participants of this research committed errors. In succession, the areas are mechanics, plural/singular form, omission of constituent, verb form, article, preposition, derivative, vocabulary, tense, 
auxiliary verb, clause formation, word order, pronoun, genitive and comparative. The areas are mentioned in order from where the most to the least errors are committed. This total number of linguistic areas as revealed in this current research is within the common range reported by other studies (see Gustilo \& Magno, 2012; Sawalmeh, 2013). Darus' (2009) research even exactly found 15 linguistic classifications of errors made by her research's participants as this current study did although the linguistics classifications she used were a little bit different.

Now, the discussion is restricted to the areas where a lot of errors have been made, namely more than ten percent. The areas are successively mechanics, plural/singular form and omission of constituent. As shown in the table, Elementary learners committed errors mostly in the linguistic classifications of mechanics (31.6\%), plural/singular form (14.5\%) and omission of constituent (14\%). Intermediate learners made the most errors in mechanics (40\%), plural/singular form (10.9\%) and derivative (9\%). Advanced learners, on the other hand, committed errors mostly in the areas of plural/singular form $(23 \%)$, omission of constituent (15.8\%) and mechanics (13\%). Therefore, across the levels mechanics, plural/singular form and omission of constitution are three linguistic areas where errors were mostly committed.

To elaborate, Elementary learners committed errors in mechanics amounting to $31.6 \%$, Intermediate learners $40 \%$ and Advanced learners 13\%. On average, the

Table 1

Distribution of the Linguistic Classifications of Errors

\begin{tabular}{|l|l|c|c|c|c|}
\hline \multirow{2}{*}{ No. } & \multirow{2}{*}{$\begin{array}{c}\text { Linguistic } \\
\text { Classifications of } \\
\text { Errors }\end{array}$} & \multicolumn{2}{|c|}{ Numbers \& Percentages of Errors } & \multirow{2}{*}{ Mean } \\
\cline { 3 - 5 } & Elementary & Intermediate & Advanced & \\
\hline 1. & Mechanics & $24(31.6 \%)$ & $22(40 \%)$ & $14(13 \%)$ & 28.2 \\
\hline 2. & Plural/Singular Form & $11(14.5 \%)$ & $6(10.9 \%)$ & $25(23 \%)$ & 16.13 \\
\hline 3. & Omission of Constituent & $11(14 \%)$ & $2(3.7 \%)$ & $17(15.8 \%)$ & 11.16 \\
\hline 4. & Verb Form & $7(9.2 \%)$ & $4(7.3 \%)$ & $13(12 \%)$ & 9.5 \\
\hline 5. & Article & $3(3.9 \%)$ & $3(5.5 \%)$ & $8(7.5 \%)$ & 5.63 \\
\hline 6. & Preposition & $3(4 \%)$ & $4(7.3 \%)$ & $6(5.6 \%)$ & 5.63 \\
\hline 7. & Derivative & $1(1.3 \%)$ & $5(9 \%)$ & $4(3.7 \%)$ & 4.67 \\
\hline 8. & Vocabulary & $4(5.3 \%)$ & $0(0 \%)$ & $8(7.5 \%)$ & 4.26 \\
\hline 9. & Tense & $6(8 \%)$ & $1(1.8 \%)$ & $3(2.8 \%)$ & 4.2 \\
\hline 10. & Auxiliary Verb & $2(2.6 \%)$ & $3(5.5 \%)$ & $4(3.7 \%)$ & 3.93 \\
\hline 11. & Clause Formation & $0(0 \%)$ & $4(7.3 \%)$ & $2(1.8 \%)$ & 3.03 \\
\hline 12. & Word Order & $2(2.6 \%)$ & $1(1.8 \%)$ & $1(0.9 \%)$ & 1.76 \\
\hline 13. & Pronoun & $1(1.3 \%)$ & $0(0 \%)$ & $2(1.8 \%)$ & 1.03 \\
\hline 14. & Genetive & $1(1.3 \%)$ & $0(0 \%)$ & $0(0 \%)$ & 0.43 \\
\hline 15. & Comparative & $0(0 \%)$ & $0(0 \%)$ & $1(0.9 \%)$ & 0.3 \\
\hline
\end{tabular}


three categories of learners' proficiencies committed errors which amounted to $28.2 \%$ in the area. In the area of plural/singular form, $14.5 \%$ errors were made by Elementary students, $10.9 \%$ by Intermediate students and $23 \%$ by Advanced students. Thus, the mean score of errors committed by the three categories of learners were $16.13 \%$. In the area of omission of constituent, Elementary learners made $14 \%$ of errors, Intermediate learners $3.7 \%$ and Advanced learners $15.8 \%$. The mean score of errors in this omission of constituent then amounted to $11.16 \%$.

As comparisons, results of other studies on errors analysis are discussed shortly here. Gustilo \& Magno (2012) found a similar result that errors in mechanics were the most common in three different levels of writing proficiency. The errors in mechanics amounted to $39.5 \%$, followed by errors in choice of word (wrong words) $13.5 \%$ and in verbs (SVA/subjectverb agreement, tenses, including verb forms) $11.8 \%$. Azimah (1998) who analyzed errors made by 30 students found that they committed a lot of errors in tenses, prepositions and subject-verb agreement. Sawalmeh (2013) reported that the three erroneous linguistic classifications Arabic speakers in his study commonly committed were successively verb tense, word order and singular/plural form (followed by subject-verb agreement as the fourth). Angwatanakul (1980) found that the commonest errors made by Thai learners were verb form, article and preposition. Lastly, Darus (2009), a Malay researcher, showed that the three most frequent errors the subjects made were consecutively in singular/plural form, verb tense, and choice of word. In her study, which used fifteen linguistic classifications as this current study did, she reported preposition and subject-verb agreement as areas where errors were common.

As seen above, mechanics and plural/singular form in which errors were commonly made as suggested in this research were also reported the same in the other research (Darus, 2009; Gustilo \& Magno, 2012; Sawalmeh, 2013). Only omission of constituent was not indicated in the other. The reason is quite likely that the other research integrated this linguistic classification into other types of error. One of the types could be prepositions, the second most common area where errors were committed in Azimah's (1998) research and the third in Angwatanakul's (1980). The other types are possibly article, the second most common area as posited by Angwatanakul (1980) and verbs, the third most common area in Gustilo \& Magno's (2012) research. To put it another way, the omission of constituent in this current research (the absence of preposition, article and the verb 'be') may be regarded as errors in prepositions, articles and verbs in the other studies. 


\subsection{Research Question 2:}

What can be learned from the profiles of linguistic classification-based errors across these three proficiency levels?

Several interesting findings were found in relationship with the profiles of linguistic classification-based errors across levels. The first finding was that Advanced students committed the least errors (only in two classifications of linguistics).Thus, they outperformed their Intermediate and Elementary peers. One was related to mechanical errors, in which Advanced learners just made 14 errors (13\%) in comparison with Intermediate and Elementary students who each made $22(40 \%)$ and 24 errors (31.6\%). The other was with respect to the error of word orders. Advanced students only made 1 error $(0.9 \%)$, while Intermediate and Elementary learners 1 error and 2 errors (1.8\% and 2.6\%) respectively. Only at these two linguistic features, did Advanced learners excel.

The second finding was the fact that Advanced learners (though committing the least number of total errors, which will be discussed later in Part 4.3) surprisingly demonstrated poor performances on seven linguistic areas as shown in Table 1. The areas were plural/singular form (23\% of total errors), omission of constituent, which indicated the simplification of function words or structure such as the omission of 'be', 'a/an/the' and 'to' $(15.8 \%)$, verb form $(12 \%)$, article $(7.5 \%)$, vocabulary $(7.5 \%)$, pronoun $(1.8 \%)$ and comparative $(0.9 \%)$. This total number of linguistic areas where Advanced learners' gave poor performances was surprisingly the most, compared with poor performances on 5 areas given by Intermediate and on 3 areas by Elementary learners. As for Intermediate students, their worst performances were in five linguistic areas: mechanics (40\%), preposition $(7.3 \%)$, derivative (9\%), auxiliary verb $(5.5 \%)$ and clause formation $(7.3 \%)$; and Elementary students just in three: tense (8\%), word order $(2.6 \%)$ and genitive $(1.3 \%)$.

To account for fact that Advanced students made errors in the most numbers of linguistic areas, it was quite likely that Advanced learners seemed to be still investigating the systems of the new language they were learning. In other words, they were testing their theories about the target language by more 'creatively' producing their own expressions and language structures (although they turn out to be deviations from adult grammar). This fact strongly indicated that this level belonged to the phase where learners were still trying to find the nature of the language they were learning by hypothesizing, thus still making many errors. This characteristic proved that Advanced learners still needed to get input of and exposure to the language they were learning. 
The third finding was related to Intermediate students, who demonstrated their poor performances just in five linguistic areas: mechanics, preposition, derivative, auxiliary verb and clause formation with the percentages already alluded to in the previous two paragraphs. This showed that they were just a little bit less 'creative' to produce their own expressions and language structures than Advanced learners. Interestingly, the data also depicted that Intermediate students outperformed the other two levels. Intermediate students got the most numbers of linguistic areas ( 6 altogether) where the least errors were made. The six areas were plural/singular form (10.9\%), omission of constituent (3.7\%), verb form $(7.3 \%)$, vocabulary $(0 \%)$, tense $(1.8 \%)$ and pronoun $(0 \%)$. This is a phenomenon worth noting, for which the underlying reasons are necessarily sought by future research.

Just to work on a possible, tentative explanation for this, the theory of language development as a Dynamic System (see de Bot, 2005, p. 14) can be used to explain the phenomenon. It is likely that in the level of Intermediate, in contrast to Elementary and Advanced level, learner language development becomes relatively a bit stable (therefore has less errors in linguistic areas/classifications). As reported by many studies on SLA, in a cline from the lowest to the highest level, learner language competence develops and changes prior to the establishment of a more stable construction (see de Bot, 2005).

The fourth finding was about the performances of Elementary students, who surprisingly performed worst on just three linguistic classifications: tense (8\%), word order $(2.6 \%)$ and genetive $(1.3 \%)$. In other words, they could outperform their peers from Advanced and Intermediate level since the former demonstrated poor performances in seven and the latter in five classifications as previously explained. On the other hand, Elementary students committed the least errors in five linguistic classifications (compared with Advanced learners who did the same in just two and Intermediate students in six classifications). Those five linguistic classifications were article (3.9\%), preposition (4\%), derivative (1.3\%), auxiliary verb $(2.6 \%)$ and clause formation $(0 \%)$. Elementary learners, therefore, performed much better than Advanced students and only a bit less than Intermediate ones at making errors in the very least linguistic classifications.

A plausible reason for this surprising phenomenon could be that Elementary learners resorted to formulaic speech (see Ellis, 1994 p. 84). They used expressions as memorized chunks such as I don't know, I think you should... ,keep in touch with, Isn't that awesome?, Don't forget to ... etc. In other words, they seemed to apply what de Bot (2005 p. 33) calls 'usage-based syntactic operations' in their writing. In these operations, they simply retrieved 
the expressions from the linguistic items that they had previously learned and stored, and then 'cut and pasted' them together as necessary for their language production.

The fifth finding of this research was connected with the mechanical type of errors. Compared with any other types, it appeared to be the highest in occurrences, especially for Elementary and Intermediate students. Out of their total errors, the former made $31.6 \%$ of errors belonging to this linguistic type; the latter, even worse, made $40 \%$. Advanced learners also committed $13 \%$ of errors - a significant number of errors too - in this linguistic type. Indonesian teachers of English should learn about this. To leave mechanics untouched in the teaching as most practitioners are inclined to because mechanical sides of writing are considered trivial is proven to be unwise.

The sixth finding of this study was related to the concepts of plural/ singular form. The concepts seemed to confuse Indonesian students across levels. This phenomenon is interesting since it has been said that in the order of acquisition, plural $-s$ in English is acquired before most of other language features as evidenced in general regularities of language acquisition (see Ellis, 1994, p. 78; Krashen \& Terrell, 1983, p. 28). In the context of Indonesian learners of English, the assertion is not thoroughly valid. Relatively high occurrences of errors of this specific linguistic feature are found in Indonesian learners. The reasons might be that their L1 cannot facilitate them to learn the feature as Bahasa Indonesia does not distinguish plural nouns and verbs from singular ones. Bahasa Indonesia sometimes only repeats a noun to indicate its plural form. Errors in this linguistic specification account for the majority - if not all - of occurrences of negative interlingual transfer errors committed by the subjects of the study. This fact will be discussed more later on.

\subsection{Research Question 3:}

What is the main source of those linguistic classifications of errors, negative interlingual or intralingual transfer?

As displayed in Table 2, intralingual transfer is responsible more for the students' error-making than negative interlingual transfer. The students of Advancedlevelgot $88.9 \%$ of errors which resulted from the former and $11.1 \%$ from the latter. In the Intermediate level, intralingual transfer caused $94.5 \%$ of errors, compared with $5.5 \%$ of errors caused by negative interlingual transfer. In the Elementary level, the cases of errors resulting from intralingual transfer $(88.2 \%)$ were still more than those caused by negative interlingual transfer $(11.8 \%)$. In conclusion, across the three proficiency levels, errors caused by intralingual transfer were more predominant than those resulting from negative interlingual transfer. 
Tabel 2

Proportions of the Negative Interlingual Transfer and Intralingual Transfer as the Sources of Errors Across the Three Proficiency Levels

\begin{tabular}{|c|c|c|c|c|c|}
\hline \multirow{2}{*}{ Levels } & \multicolumn{2}{|c|}{ Sources of Errors } & \multirow[b]{2}{*}{$\begin{array}{c}\text { Total } \\
\text { Errors }\end{array}$} & \multirow{2}{*}{$\begin{array}{c}\text { Total } \\
\text { Words } \\
\text { Written }\end{array}$} & \multirow{2}{*}{$\begin{array}{c}\text { Percentages \& } \\
\text { Frequency of } \\
\text { errors }\end{array}$} \\
\hline & $\begin{array}{c}\text { Negative } \\
\text { Interlingual }\end{array}$ & $\begin{array}{c}\text { Intralingual } \\
\text { Transfer }\end{array}$ & & & \\
\hline EL & $9 / 11.8 \%$ & $67 / 88.2 \%$ & 76 & 439 & $\begin{array}{c}17.3 \% \text { / } 1 \text { every } \\
5-6 \text { words }\end{array}$ \\
\hline INT & $3 / 5.5 \%$ & $52 / 94.5 \%$ & 55 & 462 & $\begin{array}{c}11.9 \% \text { / } 1 \text { every } \\
8-9 \text { words }\end{array}$ \\
\hline ADV & $12 / 11.1 \%$ & $96 / 88.9 \%$ & 108 & 1138 & $\begin{array}{c}9.5 \% / 1 \text { every } \\
10-11 \text { words }\end{array}$ \\
\hline
\end{tabular}

Ellis (1994, p.69) said that studies on error analysis have come up with different results as to the percentages of errors resulting from learners' first language transfer. For example, AbiSamra (2003), who grouped the errors into five classifications in the work written by 10 students, reported that just around 33\% of students' errors resulted from the negative influence of the students' first language. On the other hand, Ridha (2012), who probed into $80 \mathrm{EFL}$ college student corpus and classified the mistakes there into four taxonomies, suggested that most of the students' mistakes were owing to the transfer from the first language. However, Ellis (1994, p. 69) claims that "most studies concur that the majority of errors are intralingual". The result that intralingual transfer errors are higher than interlingual ones in this current study follows the main stream of findings as stated by Ellis (1994) above.

Table 2 also reveals the general performance of the students' achievements on errormaking across levels. As displayed in the sixth column, students of the Advanced level demonstrated the least number of total errors though they committed the most linguistic classification-based errors. Compared with the total words written, they committed $9.5 \%$ of total errors. That meant the learners made one error every $10-11$ words they wrote. Intermediate students hold the second position by committing more errors $(11.9 \%$ or one error every $8-9$ words used). Then, Elementary students come in the last position with $17.3 \%$ of total errors, which means one error every $5-6$ words they used. As such, the finding was quite typical since it was a common phenomenon where the higher the students' proficiency 
was, the fewer they would make errors. Therefore, there is nothing new in the finding since it comes as expected.

\section{CONCLUSION AND RECOMMENDATIONS}

This investigation of errors revealed that errors committed by the participants of this study covered fifteen areas of linguistic classifications. It was further found that three (mechanics, plural/singular form and omission of constituent) became the areas where most errors were made. There were other linguistic areas in which significant numbers of errors were committed. Those areas, also reported by other studies as important linguistic classifications where errors are commonly made, are consecutively verb form, article, preposition, derivative, vocabulary/word choice, tense, and auxiliary verb (unnecessary inclusion of 'be'). The area of mechanics needs to be paid extra attention to by teaching practitioners as it turns out to be the most common errors across levels in this study.

Further, this study confirms the axiom that the higher the level of learners is, the least errors he/she commits. However, when the errors are classified based on lingusitic classifications, the axiom is shaking as evidenced in the study. It turns out that Elementary students committed errors in the least linguistic areas, while Intermediate students made errors in more areas and Advanced students the most. The study has attempted to account for this interesting phenomenon. Future studies, however, are required to be done to probe into the phenomenon deeply to reveal the underlying reasons behind it.

Research on errors, especially one related to a meta-analysis, is also required in the future. As far as the present researcher is concerned, there have not been so far any standardized linguistic classifications used to analyze errors committed by learners of English. The inconsistency of results reported by studies on errors analysis might be because of the different classifications used. It is expected that meta-analysis studies, based on their investigation of the common categories used by many researchers to identify errors, can offer certain linguistic classifications which are empirically more reliable. Therefore, the results of error analysis will show more obvious patterns of common errors produced by EFL learners.

To conclude, hopefully this research on error analysis will contribute to the theory of language acquisition. The study is expected to give a clearer account of how an L2 is acquired in three different proficiency levels, especially in the context of Indonesian students learning English. For the teaching practitioners, the findings of the study can shed light on how to teach the three levels of students in order to bring better results and higher impacts on part of the learners. 


\section{References}

AbiSamra, N. (2003). An analysis of errors in Arabic speakers' English writing. In Mourtaga, $\mathrm{K}$. (Ed.), Investigating writing problems among Palestinian students studying English as a foreign language. Unpublished doctoral dissertation.

Angwatanakul, S. (1980).Relationships between communicative competence and learning achievement in the English language. Chulalongkorn Educational Review, Chulalongkorn University.

Azimah, H. (2005). Analysis of errors in composition of form one secondary school in Kuala Lumpur. Unpublished Master's thesis. Universiti Kebangsaan Malaysia, Bangi.

Brown, H.D. (1994). Principles of language learning and teaching. Englewood Cliffs: Prentice Hall. Regents. Prentice-Hall Press.

Corder, S.P. (1974). Error analysis in Allen and Corder (eds) 1974.

Corder, S.P. (1967). The significance of learners' errors. International Review of Applied Linguistics 5: 161-9.

Darus, S. (2009). Error analysis of the written English essays of secondary school students in Malaysia: A case study. Research Gate, https://www.researchgate.net/publication/235772401.

de Bot, K., Lowie, W., \& Verspoor, M. (2005). Second language acquisition. Great Britain: Routledge.

Dulay, H. \& Burt, M. (1972).Goofing, an indicator of children's second language strategies. Language Learning 22: 234-52.

Ellis, R. (1994). The study of second language acquisition. Hong Kong: Oxford University Press.

Ferris, D. (2002). Treatment of error in second language student writing. USA: Ann Arbon The University of Michigan Press.

French, F. (1949). Common errors in English. London: Oxford University Press.

George, H. (1972). Common errors in language learning: Insights from English. Rowley, Mass.: Newbury House.

Gustilo,L. \&Magno, C. (2012).Learners' errors and their evaluation: The case of Filipino ESL writers. Philippine ESL Journal, Vol. 8, February 2012 (C) 2012 Time Taylor International ISSN 1718-2298.

Hartono, R. (2001). Grammatical and mechanical errors in writing: A case study. Unpublished Master's Thesis. Bandung: Indonesia University of Education.

Krashen, S.D. \& Terrell T.D. (1983).The natural approach: Language acquisition in the classroom. Great Britain: Pergamon Press Ltd.

Lee, W. (1957).The linguistic context of language learning. English Language Teaching Journal 11: 77-85.

Richards, J.(1971). A non-contrastive approach to error analysis. English Language Teaching Journal 25: 204-19.

Richards, J. \& Platt, J. (1992).Longman dictionary of language teaching \& applied linguistics. London: Longman Group UK Limited.

Ridha, N. (2012). The effect of EFL learners' mother tongue on their writings in English: An error analysis study. Journal of the College of Arts. University of Basrah,60,22-45.

Sawalmeh, M.H.M. (2013). Error analysis of written English essays: The case of students of the Preparatory Year Program in Saudi Arabia. English for Specific Purposes World, Issue 40, vol. 14,http://www.esp-world.info

Schachter, J. \& Celce-Murcia, M. (1977).Some reservations concerning error analysis. TESOL Quarterly 11: 441-51.

Selinker, L. (1972). Interlanguage. International Review of Applied Linguistics 10: 209-31. 